\title{
Solid State NMR Investigation of the Structures and Dynamics of Poly(silylenemethylene)s
}

\author{
Shigeki Kuroki, Jun NANBA, Isao Ando, \\ Takuya Ogawa, ${ }^{*}$ and Masashi Murakami* \\ Department of Chemistry and Materials Science, Tokyo Institute of Technology, \\ Ookayama, Meguro-ku, Tokyo 152-8552, Japan \\ * Research Center, Dow Corning Asia Ltd., 603 Kishi. \\ Yamakita, Kanagawa 258-0112, Japan
}

(Received November 17, 1998)

\begin{abstract}
Poly(silylenemethylene)s with the repeating $\mathrm{Si}-\mathrm{C}$ backbone units are well-examined carbosilane polymers. We synthesized two poly(silylenemethylene)s, poly(diphenyl-silylenemethylene) (PDPhSM) and poly(methyl phenyl-silylenemethylene) (PMPhSM). These two polymers have different physical, thermal and mechanical properties. This work discusses the structures and dynamics of the $\mathrm{Si}-\mathrm{C}$ backbone and phenyl side groups of these two polymers by ${ }^{13} \mathrm{C}$ and ${ }^{29} \mathrm{Si}$ solid-state NMR and reveals relationships between the thermal and mechanical properties and between structures and dynamics of the $\mathrm{Si}-\mathrm{C}$ backbone and the side chains. KEY WORDS $\quad{ }^{13} \mathrm{C}$ and ${ }^{29} \mathrm{Si}$ Solid-State Nuclear Magnetic Resonance / Poly(silylenemethylene)s / Si-C Backbone Units / Phenyl Side Groups / Structure and Dynamics /
\end{abstract}

Silicon-based polymers have been extensively studied over the past 30 years due to their high thermal stability as well as unique optoelectrical properties. ${ }^{1,2}$ Poly(silylenemethylene)s with the repeating $\mathrm{Si}-\mathrm{C}$ backbone units are well-examined carbosilane polymers, and research can be found in the literature..$^{3-17}$ The largest interest in the study of poly(silylenemethylene)s seems to be pyrolytic profiles of these polymers to $\mathrm{Si}-\mathrm{C}$ ceramics. ${ }^{18} \mathrm{Few}$ reports have been published dealing with the material properties, such as thermal or mechanical properties rather than pyrolytic properties, of poly(silylenemethylene)s. Several reports dealing with the synthesis and pyrolytic behavior of poly(silylenemethylene)s have been published, ${ }^{19-26}$ and our recent articles report the synthesis and basic physical properties and thermal and mechanical properties of poly(diphenylsilylenemethylene) (PDPhSM) and poly(methyl phenylsilylenemethylene) (PMPhSM). ${ }^{27-29}$ PDPhSM is a crystalline polymer with poor solubility in common organic solvents. ${ }^{27}$ The melting temperature of PDPhSM is about $350^{\circ} \mathrm{C}$, and the glass transition temperature is ca. $140^{\circ} \mathrm{C}^{27}$ The weight of PDPhSM remains almost unchanged by heating up to $c a .400^{\circ} \mathrm{C}$ in air and in nitrogen. ${ }^{28} \mathrm{PMPhSM}$ is an amorphous polymer with good solubility in common organic solvents. ${ }^{29}$ The glass transition temperature of $\mathrm{PMPhSM}$ is around $20^{\circ} \mathrm{C}$ and it depends on molecular weight and the tacticity. ${ }^{29}$ The weight of PMPhSM remained almost unchanged by heating up to $c a .400^{\circ} \mathrm{C}$ in air and in nitrogen. ${ }^{29}$ Thus the thermal and mechanical properties of these two polymers are very different despite containing the same $\mathrm{Si}-\mathrm{C}$ backbone. Differences of these properties come from differences of structures and the dynamics of the $\mathrm{Si}-\mathrm{C}$ backbone and side-chains in the solid-state. But there are no studies on molecular structures or molecular motion of PDPhSM and PMPhSM in the solid-state.

Solid-state high-resolution nuclear magnetic resonance (NMR) spectroscopy has become an enormously fruitful technique in the study of molecular structure and motion of polymers in the solid-state. ${ }^{30,31}$ In particular, it is useful for structural and molecular motion studies of polymers $^{32}$ with poor solubility in solvents such as PDPhSM.

This paper reports the ${ }^{13} \mathrm{C}$ and ${ }^{29} \mathrm{Si}$ solid-state NMR spectra of PDPhSM and PMPhSM and discusses the main-chain and side-chain structures and molecularmotion of PDPhSM and PMPhSM.

\section{EXPERIMENTAL}

\section{Preparation of Polymers}

$\mathrm{PMPhSM}$ and PDPhSM were prepared as previously reported..$^{27-29}$ The structure of the polymer is as follows.<smiles>CC(C)(C)C[Si](c1ccccc1)(c1ccccc1)C(C)(C)C</smiles>

PDPhSM

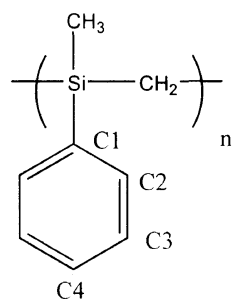

PMPhSM
The tacticity of PMPhSM $(0.31(\mathrm{rr}): 0.46(\mathrm{mr}): 0.23(\mathrm{~mm}))$ was determined from the solution state ${ }^{13} \mathrm{C}$ NMR spectrum.

\section{Solid-State NMR Measurements}

NMR spectra were recorded on a Bruker DSX-300 NMR spectrometer. The observed frequencies of ${ }^{13} \mathrm{C}$ and ${ }^{29} \mathrm{Si}$ are $75.6 \mathrm{MHz}$ and $59.6 \mathrm{MHz}$, respectively. The 90-degree pulse of ${ }^{1} \mathrm{H}$ was $4.7 \mu \mathrm{s}$, and contact times of the cross polarization experiment were $2 \mathrm{~ms}$ for ${ }^{13} \mathrm{C}$ and $5 \mathrm{~ms}$ for ${ }^{29} \mathrm{Si}$, respectively. The repetition time is $300 \mathrm{~s}$ 

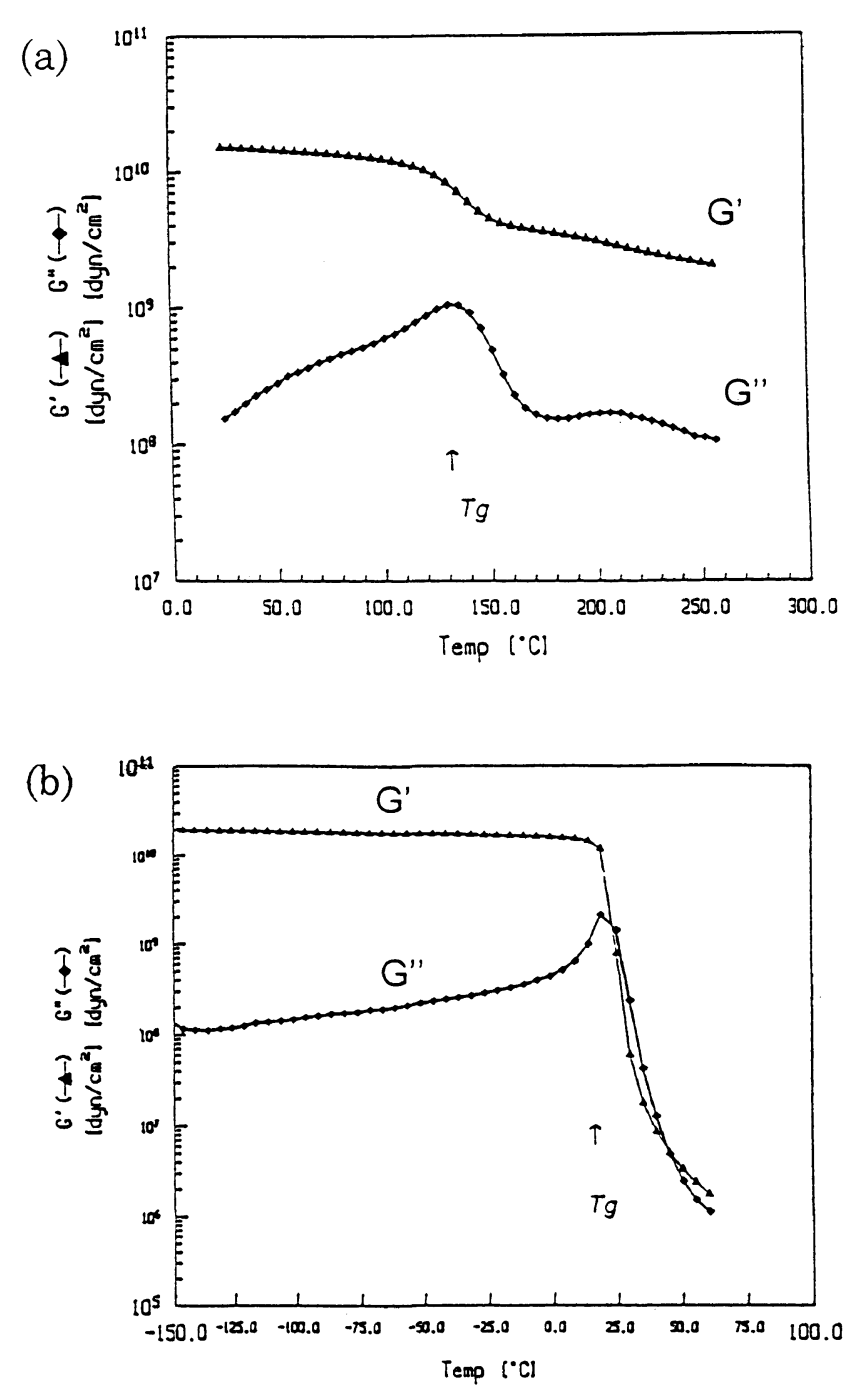

Figure 1. Temperature dependence of the storage modulus $G^{\prime}$ and loss modulus $G^{\prime \prime}$ of PDPhSM (a) and PMPhSM (b) at a constant frequency of $6.28 \mathrm{rad} \mathrm{s}^{-1}$ and constant strain of $1 \%$.

and pulse length is $1 \mu \mathrm{s}$ for ${ }^{29} \mathrm{Si} \mathrm{DD} / \mathrm{MAS}$ experiments. The dipolar dephasing delay time was $400 \mu$ s for the ${ }^{13} \mathrm{C} \mathrm{CP}+\mathrm{DDph}$ (dipolar dephasing) experiment. ${ }^{13} \mathrm{C}$ chemical shifts were calibrated indirectly through the adamantane peak observed to low frequency $(29.5 \mathrm{ppm}$ relative to tetramethylsilane), and ${ }^{29} \mathrm{Si}$ chemical shifts were calibrated indirectly through the polydimethylsilane peak ( $-33.8 \mathrm{ppm}$ relative to tetramethylsilane).

\section{WAXD Analysis}

Wide angle X-ray diffraction (WAXD) was performed with a JEOL JDX-3530 diffractometer using Ni-filtered $\mathrm{Cu}-K_{\alpha}$ radiation. Intensity distributions $\left(5^{\circ}<2 \theta<35^{\circ}\right)$ were recorded in the reflection mode by a goniometer equipped with a monochrometer.

\section{Dynamic Mechanical Properties Measurements}

Dynamic mechanical properties were examined using a Rheometrics RDA II dynamic analyzer in torsion mode. Each specimen $(10 \times 30 \times 1 \mathrm{~mm})$ was prepared by compression molding.
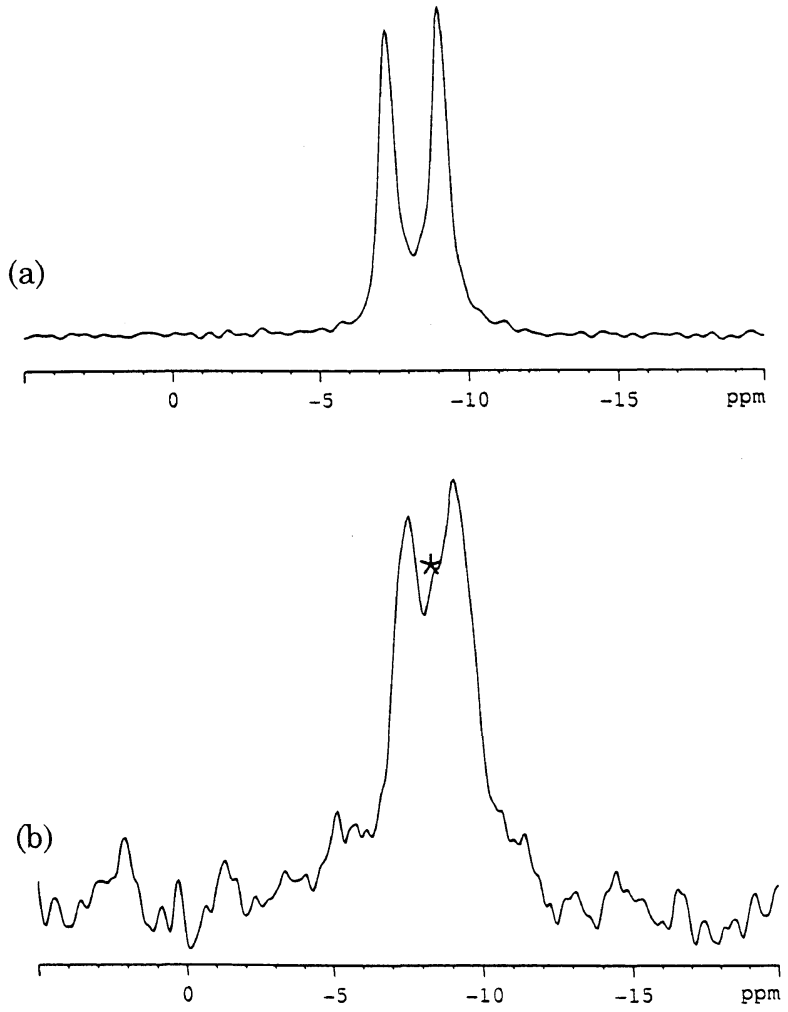

Figure 2. ${ }^{29} \mathrm{Si} \mathrm{CP} / \mathrm{MAS}$ (a) and ${ }^{29} \mathrm{Si} \mathrm{DD} / \mathrm{MAS}$ (b) spectrum of $\mathrm{PDPhSM}$ at room temperature. The signal of the non-crystalline region is indicated with an asterisk.

\section{RESULTS AND DISCUSSION}

\section{Dynamic Mechanical Properties of PDPhSM and PMPhSM}

Figure 1 shows the temperature dependence of storage moduli $\left(G^{\prime}\right)$ and loss moduli $\left(G^{\prime \prime}\right)$ for PDPhSM (a) and $\mathrm{PMPhSM}$ (b), respectively. The obvious transition at $140^{\circ} \mathrm{C}$ observed for storage moduli $\left(G^{\prime}\right)$ and loss moduli $\left(G^{\prime \prime}\right)$ is assigned to the glass transition, and other transitions at around $60^{\circ} \mathrm{C}$ and $210^{\circ} \mathrm{C}$ are observed for $G^{\prime \prime}$ in the case of PDPhSM. An ambiguous transition at around $-120^{\circ} \mathrm{C}$, in addition to clear transition caused by the glass transition at $20^{\circ} \mathrm{C}$, was observed for the storage moduli $\left(G^{\prime}\right)$ and loss moduli $\left(G^{\prime \prime}\right)$ in the case of PMPhSM. The storage moduli $\left(G^{\prime}\right)$ of PDPhSM decrease by only one order of magnitude at the glass transition, but those of PMPhSM decrease by over three orders of magnitude at the glass transition.

\section{Solid-State NMR Studies of PDPhSM at Room Tem- perature}

Figure 2(a) shows the ${ }^{29} \mathrm{Si} \mathrm{CP} / \mathrm{MAS}$ NMR spectrum of PDPhSM at room temperature. The ${ }^{29} \mathrm{Si} \mathrm{CP} / \mathrm{MAS}$ NMR spectrum contains two sharp signals at $-7.6 \mathrm{ppm}$ and $-9.3 \mathrm{ppm}$ and the intensity ratio of these two signals is about $1: 1 . T_{1}$ of the signal at $-7.6 \mathrm{ppm}$ is $273 \mathrm{~s}$, and that of the signal at $-9.3 \mathrm{ppm}$ is $306 \mathrm{~s}$, so that these signals observed in the ${ }^{29} \mathrm{Si} \mathrm{CP} / \mathrm{MAS}$ experiment come from the crystalline region of PDPhSM. Figure 2(b) shows the ${ }^{29} \mathrm{Si}$ DD/MAS NMR spectrum of PDPhSM at room temperature. Compared with the ${ }^{29} \mathrm{Si} \mathrm{CP} / \mathrm{MAS}$ NMR spectrum, a shoulder signal at $-8.5 \mathrm{ppm}$ was observed in the ${ }^{29} \mathrm{Si}$ DD/MAS NMR spectrum, which 


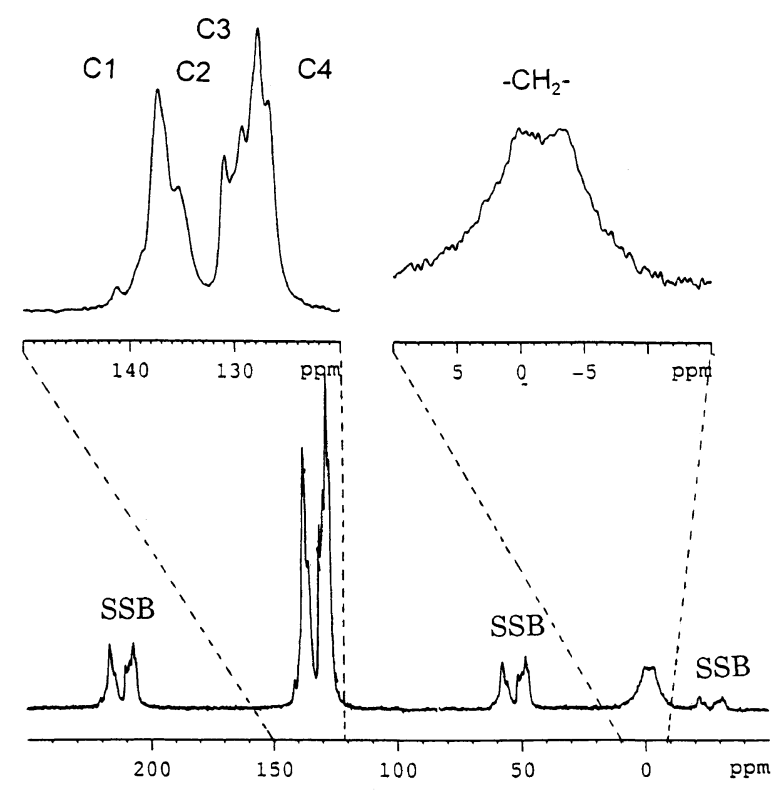

Figure 3. ${ }^{13} \mathrm{C} \mathrm{CP} / \mathrm{MAS}$ NMR spectra of PDPhSM at room temperature. SSB means a spinning sideband.
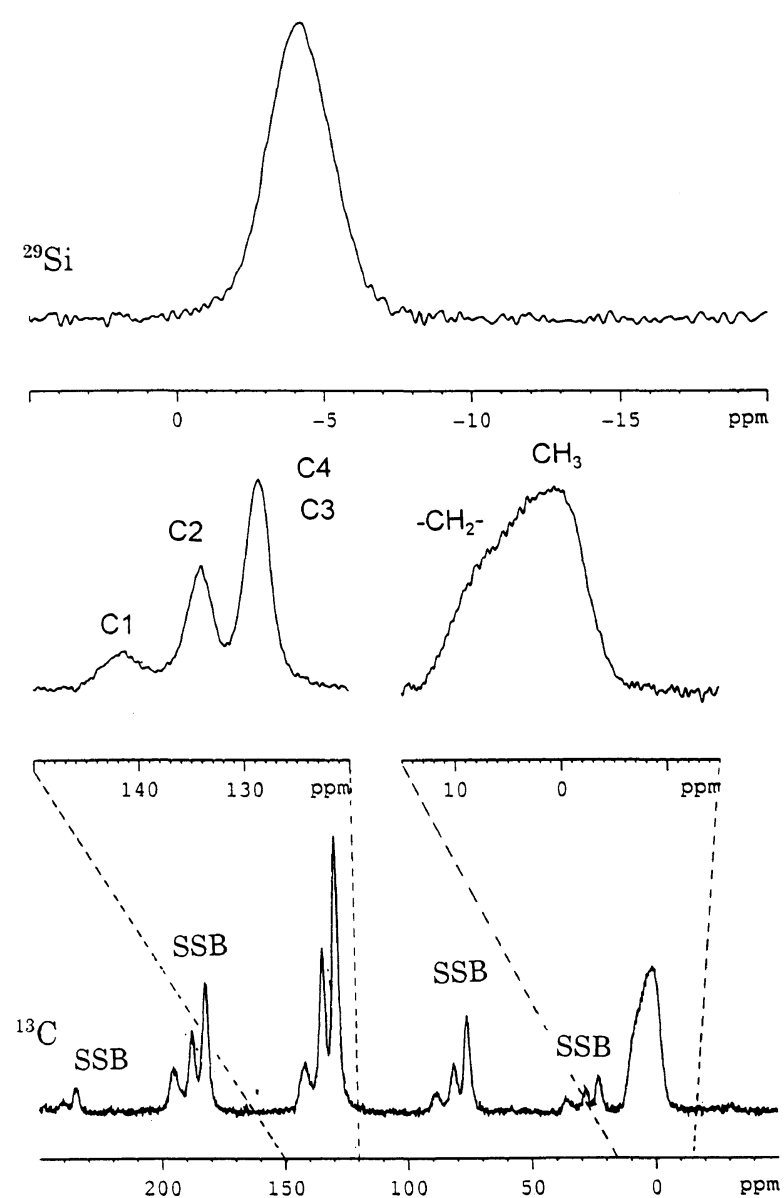

Figure 4. ${ }^{29} \mathrm{Si}$ and ${ }^{13} \mathrm{C} \mathrm{CP} / \mathrm{MAS} \mathrm{NMR}$ spectra of $\mathrm{PMPhSM}$ at room temperature. SSB means spinning sideband.

was assigned to the noncrystalline region of PDPhSM. From these results, there exist two conformational isomers in the crystalline region of PDPhSM and the peaks at $-7.6 \mathrm{ppm}$ and $-9.3 \mathrm{ppm}$ were assigned to these two conformational isomers in the crystalline region.

The phenyl region (from 120 to $150 \mathrm{ppm}$ ) of the ${ }^{13} \mathrm{C}$ (d)

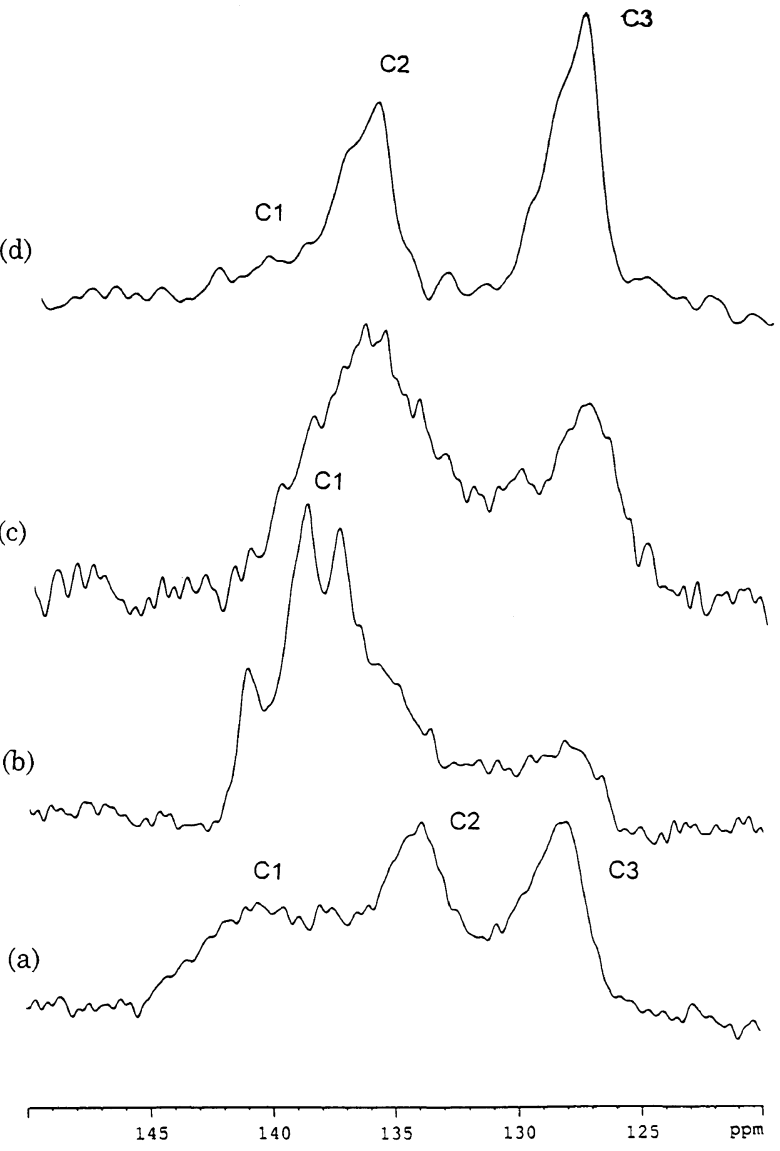

Figure 5. ${ }^{13} \mathrm{C} \mathrm{CP}+\mathrm{DDph}$ NMR spectra in the phenyl region for $\mathrm{PMPhSM}$ (a) at room temperature and PDPhSM at room temperature (b), $113^{\circ} \mathrm{C}$ (c), and $226^{\circ} \mathrm{C}(\mathrm{d})$.

CP/MAS NMR spectrum of PDPhSM shown in Figure 3 is very complicated in structure and contains several lines so that motion of the phenyl rings of PDPhSM is restricted at room temperature. There are two peaks at $0.0 \mathrm{ppm}$ and $-3.1 \mathrm{ppm}$ assigned to the methylene carbons of the main chain in a similar manner with the ${ }^{29} \mathrm{Si}$ result. There thus exist two conformational isomers in the crystalline region of PDPhSM.

Solid-State NMR Studies of PMPhSM at Room Temperature

Figure 4 shows ${ }^{29} \mathrm{Si}$ and ${ }^{13} \mathrm{C} \mathrm{CP} / \mathrm{MAS}$ NMR spectra of $\mathrm{PMPhSM}$ at room temperature. From the ${ }^{29} \mathrm{Si} \mathrm{CP} /$ MAS NMR spectrum, only one broaden line is observed, compared with PDPhSM, at $-4.5 \mathrm{ppm}$. This polymer is an amorphous polymer so that this broad signal means a conformational distribution along the $\mathrm{Si}-\mathrm{C}$ backbone.

Peaks at $141.7 \mathrm{ppm}(\mathrm{C} 1), 134.0 \mathrm{ppm}(\mathrm{C} 2), 128.5 \mathrm{ppm}$ (C3 and C4), $7.0 \mathrm{ppm}$ (the methylene carbons) and $0.5 \mathrm{ppm}$ (the methyl carbons) are observed in the ${ }^{13} \mathrm{C}$ CP/MAS NMR spectrum. The broad signal assigned to the methylene carbons of the main-chain implies conformational distribution along the $\mathrm{Si}-\mathrm{C}$ backbone in a similar manner for ${ }^{29} \mathrm{Si}$.

\section{Motion of Phenyl Rings of PDPhSM and PMPhSM}

Figure 5 shows the ${ }^{13} \mathrm{C} \mathrm{CP}+\mathrm{DDph}$ NMR spectra in the phenyl region for PMPhSM, and PDPhSM at room temperature, $113^{\circ} \mathrm{C}$ and $226^{\circ} \mathrm{C}$, respectively. Dipolar/ 


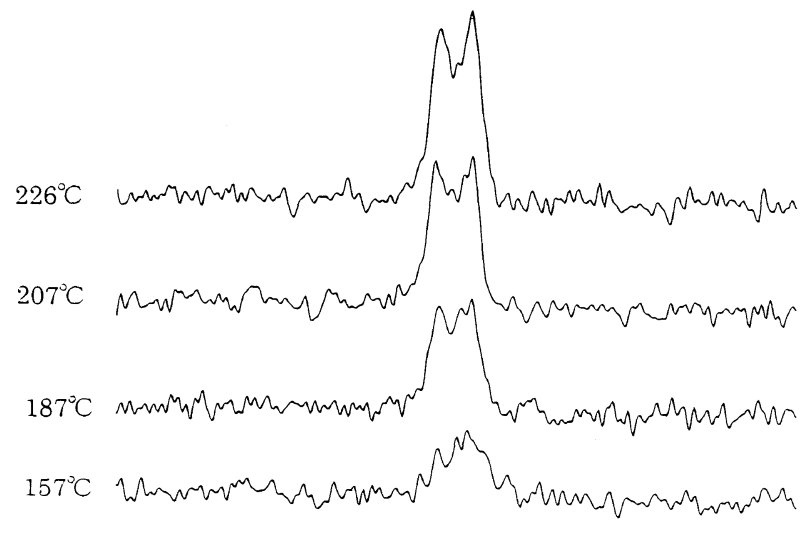

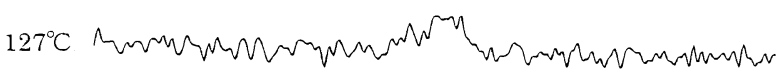

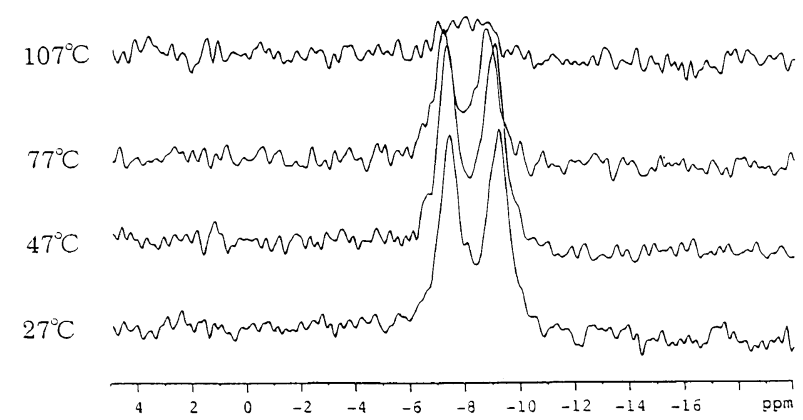

Figure 6. ${ }^{29} \mathrm{Si} \mathrm{CP} / \mathrm{MAS}$ NMR spectra of PDPhSM at various temperatures. Each spectrum was recorded for 56 scans and repetition time of $20 \mathrm{~s}$

dephasing spectra are obtained by inserting a dephasing period between the CP period and detection. During the dephasing period, the carbons with directly attached hydrogens undergo rapid dephasing (on a time scale of tens of $\mu \mathrm{s}$ ); and hence their ${ }^{13} \mathrm{C}$ magnetizations are $\mathrm{dr}$ amatically depressed before ${ }^{13} \mathrm{C}$ detection. Since sometimes rapid rotation of a methyl group or a phenyl group dramatically attenuates ${ }^{1} \mathrm{H}-{ }^{13} \mathrm{C}$ magnetic dipolar interactions, dipolar-dephasing spectra of the phenyl region are very useful to evaluate the motion of the phenyl group. ${ }^{32}$

The three signals at $141.7 \mathrm{ppm}, 134.0 \mathrm{ppm}$, and 128.5 ppm observed in the ${ }^{13} \mathrm{C} \mathrm{CP}+$ DDph NMR spectrum of PMPhSM (Figure 5(a)), are assigned to the $\mathrm{C} 1, \mathrm{C} 2$, and C3 carbons, respectively. This shows that the dipole-dipole interaction with ${ }^{1} \mathrm{H}$ vanishes due to the flip-flop motion of the phenyl ring of PMPhSM at room temperature.

Three or more sharp signals assigned to the $\mathrm{C} 1$ carbons with directly attached no hydrogen and very small signals assigned to the $\mathrm{C} 2$ and $\mathrm{C} 3$ are observed in PDPhSM at room temperature (Figure 5(b)). This indicates that the flip-flop motion of the phenyl rings of PDPhSM is restricted at room temperature, and more than three magnetically unequal phenyl rings exist at room temperature. In the ${ }^{13} \mathrm{C} \mathrm{CP}+\mathrm{DDph} \mathrm{NMR}$ spectrum of $\mathrm{PDPhSM}$ at $113^{\circ} \mathrm{C}$, signals corresponding to $\mathrm{C} 2$ and $\mathrm{C} 3$ are observed, but the signal intensities are smaller than those at room temperature. This suggests that the flipflop motion of the phenyl rings of PDPhSM starts at this temperature but motion is not rapid enough to

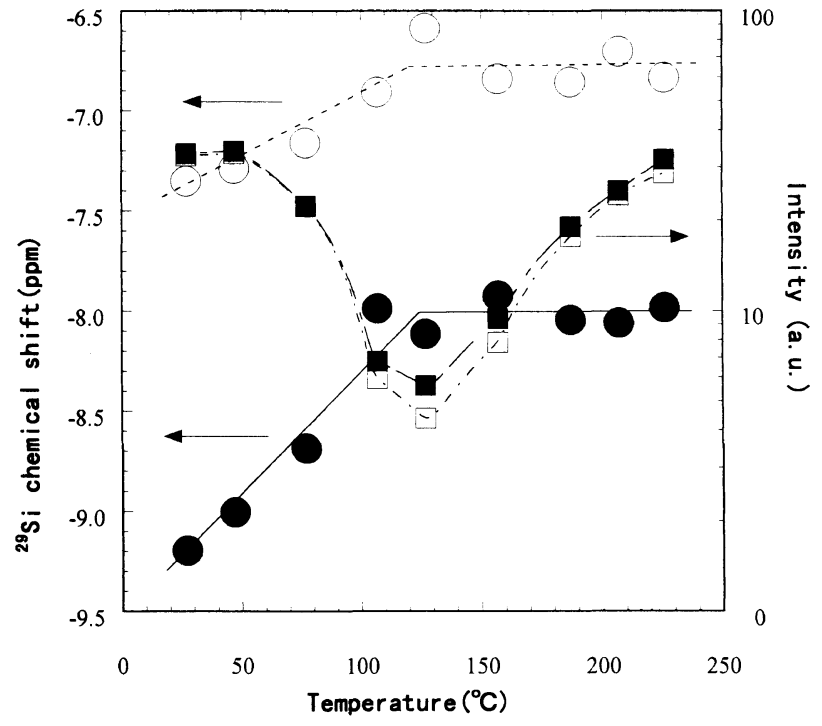

Figure 7. Change of ${ }^{29} \mathrm{Si}$ chemical shifts and relative intensities of two signals of PDPhSM at various temperatures from $27^{\circ} \mathrm{C}$ to $226^{\circ} \mathrm{C}$. $(\bigcirc$, chemical shift of lower frequency signal; $\bigcirc$, chemical shift of higher frequency signal; $\square$, intensity of lower frequency signal; intensity of higher frequency signal.)

remove ${ }^{1} \mathrm{H}-{ }^{13} \mathrm{C}$ dipole-dipole interactions completely. Signals corresponding to $\mathrm{C} 2$ and $\mathrm{C} 3$ are obviously observed in the ${ }^{13} \mathrm{C} \mathrm{CP}+\mathrm{DDph}$ NMR spectrum of $\mathrm{PDPhSM}$ at $226^{\circ} \mathrm{C}$, so that the motion of phenyl rings is enough to remove ${ }^{1} \mathrm{H}-{ }^{13} \mathrm{C}$ dipole-dipole interactions.

\section{${ }^{29} \mathrm{Si}$ Variable Temperature CP/MAS Experiments on PDPhSM}

Figure 6 shows the ${ }^{29} \mathrm{Si} \mathrm{CP} / \mathrm{MAS}$ NMR spectra of $\mathrm{PDPhSM}$ at $27^{\circ} \mathrm{C}$ to $226^{\circ} \mathrm{C}$. Each spectrum was recorded at 56 scans and repetition time of $20 \mathrm{~s}$. Plots of the ${ }^{29} \mathrm{Si}$ chemical shifts and relative intensities of the PDPhSM signals are presented in Figure 7 . The lower frequency peak ( $-9.3 \mathrm{ppm}$ at room temperature) moves to high frequency by $1.2 \mathrm{ppm}$ with increase in temperature below $130^{\circ} \mathrm{C}$. The chemical shifts are unchanged above $130^{\circ} \mathrm{C}$. The higher frequency peak $(-7.6 \mathrm{ppm}$ at room temperature) moves to high frequency by $0.6 \mathrm{ppm}$ with increase in temperature below $130^{\circ} \mathrm{C}$. The chemical shifts are unchanged above $130^{\circ} \mathrm{C}$. Both signals have intensity minima at about $130^{\circ} \mathrm{C}$, so this polymer has motion of the several tens of $\mathrm{kHz}$ which dramatically attenuates ${ }^{1} \mathrm{H}$ dipolar interactions at $130^{\circ} \mathrm{C}$. From the ${ }^{13} \mathrm{C}$ $\mathrm{CP}+\mathrm{DDph}$ NMR experiment which shows that the flip-flop motion of the phenyl rings of PDPhSM starts at $113^{\circ} \mathrm{C}$, this motion with several tens of $\mathrm{kHz}$ corresponds to the flip-flop motion of the phenyl rings. Loss of storage moduli $\left(G^{\prime}\right)$ at $140^{\circ} \mathrm{C}$ comes from the flip-flop motion of the phenyl rings.

Above $T_{\mathrm{g}}$ at $140^{\circ} \mathrm{C}$, obtained by the storage moduli $\left(G^{\prime}\right)$ and loss moduli $\left(G^{\prime \prime}\right)$, there are still two signals assigned to the two conformational isomers. This shows that this polymer has no micro-Brownian motion of the $\mathrm{Si}-\mathrm{C}$ backbone and there still exist two conformational isomers above $T_{\mathrm{g}}$ obtained by storage moduli $\left(G^{\prime}\right)$ and loss moduli $\left(G^{\prime \prime}\right)$.

Figure 8 shows the intensity distribution for the WAX diffraction of $\mathrm{PDPhSM}$ at $25^{\circ} \mathrm{C}, 100^{\circ} \mathrm{C}, 200^{\circ} \mathrm{C}$, and $300^{\circ} \mathrm{C}$. No significant change in diffraction was found 


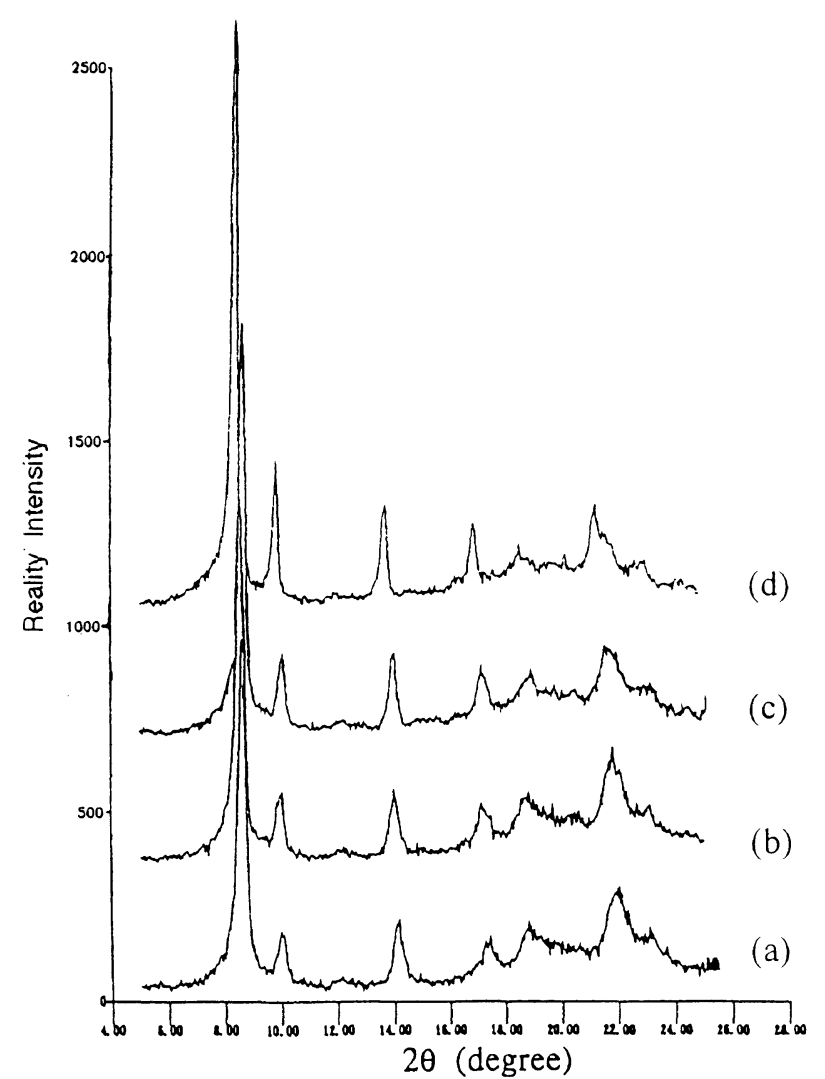

Figure 8. Wide-angle $\mathrm{X}$-ray diffractograms of $\mathrm{PDPhSM}$ at $25^{\circ} \mathrm{C}$ (a), $100^{\circ} \mathrm{C}(\mathrm{b}), 200^{\circ} \mathrm{C}(\mathrm{c})$, and $300^{\circ} \mathrm{C}(\mathrm{d})$.

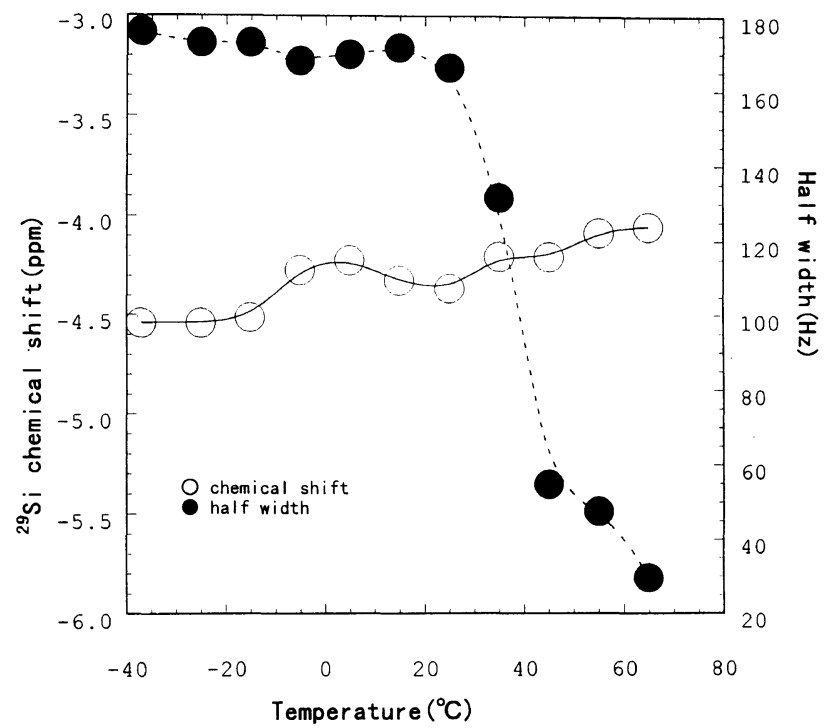

Figure 9. Plots of the ${ }^{29} \mathrm{Si}$ chemical shifts and half widths of the $\mathrm{PMPhSM}$ signal at various temperatures from $-37^{\circ} \mathrm{C}$ to $65^{\circ} \mathrm{C}$.

from $25^{\circ} \mathrm{C}$ to $200^{\circ} \mathrm{C}$, but every peak position shifted to a smaller $2 \theta$ value at $300^{\circ} \mathrm{C}$. The strongest maximum of the diffraction patterns between $25^{\circ} \mathrm{C}$ and $200^{\circ} \mathrm{C}$ is around $2 \theta=8.7$ and spacing is $10.2 \AA$. The strongest maximum of the diffraction patterns at $300^{\circ} \mathrm{C}$ was around $2 \theta=8.5$, and $d$ spacing was $10.4 \AA$. This comes from increase in inter-chain distance of the neighbouring polymer at $300^{\circ} \mathrm{C}$ which is responsible for side-chain phenyl ring motion. The ${ }^{29} \mathrm{Si}$ NMR chemical shift changes with increase in temperature. This seems to arise from the lengthening of the inter-chain distance of neighbouring polymer which is responsible for side-chain phenyl ring motion.

\section{${ }^{29}{ }^{i} i$ Variable Temperature $C P / M A S$ Experiments on PMPhSM}

Figure 9 shows plots of the chemical shifts and half width of ${ }^{29} \mathrm{Si}$ NMR signals of PMPhSM at various temperatures from $-37^{\circ} \mathrm{C}$ to $65^{\circ} \mathrm{C}$. The chemical shift moved low frequency for $0.2 \mathrm{ppm}$ with increase in temperature. The half height width of NMR signal from $-37^{\circ} \mathrm{C}$ to $25^{\circ} \mathrm{C}$ is about $170 \mathrm{~Hz}$, but above $45^{\circ} \mathrm{C}, 50 \mathrm{~Hz}$. $T_{\mathrm{g}}$ of this polymer is about $20^{\circ} \mathrm{C}$ obtained by storage moduli and loss moduli. The broad signal below $T_{\mathrm{g}}$ means conformational distribution along the $\mathrm{Si}-\mathrm{C}$ backbone and a micro-Brownian motion of the $\mathrm{Si}-\mathrm{C}$ backbone of PMPhSM starts above $T_{\mathrm{g}}$. This motion causes the half width to decrease.

\section{CONCLUSIONS}

Based on the results of ${ }^{29} \mathrm{Si}$ and ${ }^{13} \mathrm{C}$ solid-state NMR, we conclude that PDPhSM has two conformational isomers in the crystalline region and motion of the phenyl rings is restricted at room temperature. Above $T_{\mathrm{g}}$, at $140^{\circ} \mathrm{C}$, motion of the phenyl rings starts and inter-chain distance of the neighboring polymer lengthens, but there is no micro-Brownian motion of the $\mathrm{Si}-\mathrm{C}$ backbone and there still exists two conformational isomers. PMPhSM has conformational distribution along the $\mathrm{Si}-\mathrm{C}$ backbone and there is motion of phenyl rings at room temperature. The micro-Brownian motion of the $\mathrm{Si}-\mathrm{C}$ backbone of PMPhSM starts above $T_{\mathrm{g}}$.

Acknowledgments. This study was performed by the Tokyo Institute of Technology and Dow Corning Asia Ltd., under the management of the Japan Chemical Innovation Institute as a part of the Industrial Science and Technology Frontier Program supported by the New Energy and Industrial Technology Development Organization.

\section{REFERENCES}

1. M. Zeldin, K. J. Wynne, and H. R. Allcock, Ed., "Inorganic and Organometallic Polymers," ACS Symp. Ser. 360, American Chemical Society, Washington, D.C., 1998.

2. J. M. Zeigler and F. W. G. Fearon, Ed., "Silicon-Based Polymer Science," Adv. Chem. Ser. 224, American Chemical Society, Washington, D.C., 1990.

3. D. R. Weyenberg and L. E. Nelson, J. Org. Chem., 30, 2618 (1965).

4. W. A. Kriner, J. Org. Chem., 29, 1601 (1964); J. Polym. Sci., Part $A-1,4,444$ (1966).

5. N. S. Nametkin, V. M. Vdovin, and V. I. Zav'yalov, Dokl. Akad. Nauk SSSR, 162, 824 (1965); Proc. Acad. Sci. USSR, 545 (1965).

6. N. S. Nametkin, V. M. Vdovin, and A. V. Zelenaya, Dokl. Akad. Nauk SSSR, 162, 824 (1965); Proc. Acad. Sci. USSR, 545 (1965).

7. N. S. Nametkin, V. A. Poletaev, V. I. Zav'yalov, and V. M. Vdovin, Dokl. Akad. Nauk SSSR, 198, 1096 (1971); Proc. Acad. Sci. USSR, 502 (1971).

8. N. S. Nametkin, E. D. Babich, V. N. Karel'skii, and V. M. Vdovin, Izu. Akad. Nauk SSSR, Ser. Khim., 1033 (1971); Bull. Akad. Sci. USSR, Chem. Ser., 948 (1971).

9. V. A. Poletaev, V. M. Vdovin, and N. S. Nametkin, Dokl. Akad. Nauk SSSR, 203, 1324 (1972); Proc. Acad. Sci. USSR, 379 (1972).

10. V. A. Poletaev, V. M. Vdovin, and N. S. Nametkin, Dokl. Akad. Nauk SSSR, 208, 1112 (1973); Proc. Acad. Sci. USSR, 128 (1973). 
11. N. S. Nametkin and V. M. Vdovin, Izu. Akad. Nauk SSSR, Ser. Khim., 1153 (1974); Bull. Akad. Sci. USSR, Chem. Ser., 1092 (1974).

12. B. V. Lebedev, I. B. Rabinovich, and N. S. Lebedev, Dokl. Akad. Nauk SSSR, 239, 1140 (1978).

13. H.-J. Wu and L. V. Interrante, Chem. Mater., 1, 564 (1989).

14. H.-J. Wu and L. V. Interrante, Macromolecules, 25, 1840 (1992).

15. L. V. Interrante, H.-J. Wu, T. Apple, B. Ziemann, D. M. Narsavage, and K. Smith, J. Am. Chem. Soc., 116, 12085 (1994).

16. W. Habel, L. Mayer, and P. J. Sartori, Organomet. Chem., 474, 63 (1994).

17. I. L. Rushkin and L. V. Interrante, Macromolecules, 28, 5160 (1995).

18. R. M. Laine and F. Babonneau, Chem. Mater., 5, 260 (1993).

19. R. W. Lenz, Adv. Polym. Sci., 107, 1 (1993).

20. M. Okada, K. Aoi, S. Ito, and M. Atsumi, Kobunshi Ronbunshu, 30, 703 (1993)

21. M. Okada, S. Ito, K. Aoi, and M. Atsumi, J. Appl. Polym. Sci., 51, 1035 (1994).

22. M. Okada, S. Ito, K. Aoi, and M. Atsumi, J. Appl. Polym. Sci., 51, 1045 (1994).
23. M. Atsumi and M. Okada, Polvm. J., 24, 1109 (1992).

24. P. Stoss and R. Hemmer, Adv. Carbohydr. Chem. Biochem., 49, 93 (1991).

25. S. K. Dirlikov, "Agricultural and Synthetic Polymers," ACS Symposium Series 433, J. E. Glass and G. Swift, Ed., American Chemical Society, Washington, D.C., 1980, p 176.

26. S. K. Dirlikov, "Emerging Technologies for Materials and Chemicals from Biomass," ACS Symposium Series 476, R. M Rowell, T. P. Schultz, and R. Narayan, Ed., American Chemical Society, Washington, D.C., 1992, p 231.

27. T. Ogawa, M. Tachikawa, N. Kushibuki, and M. Murakami, $J$. Polym. Sci., Part A: Polym. Chem., 33, 2821 (1995).

28. T. Ogawa and M. Murakami, J. Polym. Sci., Part B: Polym. Phys., 34, 1317 (1996).

29. T. Ogawa and M. Murakami, Chem. Mater., 8, 1260 (1996).

30. T. Takayama and I. Ando, J. Molecular Structure, 222, 275 (1990).

31. W. H. Spiess, Coll. Polm. Sci., 261, 193 (1983).

32. S. Kuroki, K. Okita, T. Kakigano, J. Ishikawa, and M. Itoh, Macromolecules, 31, 2804 (1998). 